\title{
Oral and Systemic Comorbidities and its Relation to Cluster of Differentiation 4 Counts in Human Immunodeficiency Virus Patients on Highly Active Antiretroviral Therapy: An Observational Study
}

\author{
Ceena E Denny ${ }^{1}$, John Ramapuram ${ }^{2}$, Thattil S Bastian ${ }^{3}$, Almas Binnal ${ }^{4}$, Srikant Natarajan ${ }^{5}$, Nanditha Sujir $^{6}$
}

\begin{abstract}
Aims: Oral and systemic comorbidities are common in human immunodeficiency virus (HIV)/acquired immunodeficiency syndrome (AIDS) and are considered to be important predictors of the disease. Cluster of differentiation 4 (CD4) count serves as an important marker for the progression of HIV to AIDS. Our objective was to correlate the oral and systemic comorbidities associated with HIV infection with CD4 count in patients on highly active antiretroviral therapy (HAART).

Materials and methods: This was an observational study among $110 \mathrm{HIV}$-diagnosed patients. The oral and systemic comorbidities were noted and compared to their CD4 counts. A Chi-square analysis was carried out to see the association of oral manifestations.

Results: Among the study subjects, 50 (45.5\%) participants had a CD4 count of $>500$ cells $/ \mu \mathrm{L}, 46$ (41.8\%) patients had a CD4 count of $200-499$ cells $/ \mu \mathrm{L}$, whereas $14(12.7 \%)$ had $<200$ cells $/ \mu \mathrm{L}$. The major oral manifestations observed were dental caries $(n=30,60 \%)$, periodontitis $(n=25$, $50 \%)$, and lipoatrophy $(n=25,50 \%)$ in patients with CD4 $>500$ cells/ $\mu \mathrm{L}$; dental caries $(n=28,60.90 \%)$, intraoral pigmentation $(n=23,50 \%)$, and periodontitis $(n=20,43.50 \%)$ in patients with a CD4 count between 200 and 499; and dental caries $(n=9,64.30 \%)$, periodontitis $(n=7$, $50 \%)$, and candidiasis $6(42.90 \%)$ among subjects with CD4 counts $<200$. The most common systemic comorbidity observed was tuberculosis $(p<0.001)$ and pneumonia $(p<0.003)$.

Conclusion: Early intervention strategies in diagnosis and management for HIV-infected individuals have shown promising results. With the advent of HAART, the quality of life has significantly improved.

Clinical significance: The prevalence of oral and systemic comorbidity among HIV-infected patients have declined since the advent of HAART. Oral and general physicians should be able to identify and treat the patients at the earliest, which in turn could reduce the morbidity and mortality rates among those infected with HIV.

Keywords: CD4 count, Highly active antiretroviral therapy, Human immunodeficiency virus, Systemic comorbidity.

World Journal of Dentistry (2019): 10.5005/jp-journals-10015-1642
\end{abstract}

\section{INTRODUCTION}

Human immunodeficiency virus (HIV) infection remains an enigma in today's growing world. There is a 32\% decline of new cases of HIV infections in the world. ${ }^{1}$ As per the prevalence rates of HIV reported from India, there was a decline from $0.38 \%$ in $2001-2003$ to $0.22 \%$, and in Karnataka, it was about $0.47 \%$ among the adults in 2017. There was also a $71 \%$ decline in acquired immunodeficiency syndrome (AIDS)-related deaths. ${ }^{2}$

The hallmark feature in determining the progression of HIV infection to AIDS is dependent on the depletion of cluster of differentiation $(C D)$ count. The virus remains in the body in both latent and replicative form. The T lymphocytes plays an important role in immune mechanisms, as they thwart and keep our bodies free from infections, and are also potential target cells of HIV. ${ }^{3}$ CD4+ T cells are mainly present in the GI tract, followed by lymph nodes and other lymphatic tissues rather than the peripheral blood. ${ }^{4}$ The destruction of the lymphocytes reduces the ability of the body to fight infections, thereby predisposing the patient susceptible to opportunistic infections. ${ }^{5}$ The initial signs of immunosuppression occur when the CD4 count is lower than 500 cells $/ \mathrm{mm}^{3}$, while the number of circulating CD4 cells ranges from 600 to 1,600 cells $/ \mathrm{mm}^{3}$ in a healthy individual. ${ }^{6}$
1,4,6 Department of Oral Medicine and Radiology, Manipal College of Dental Sciences, Mangalore, Manipal Academy of Higher Education, Manipal, Karnataka, India

${ }^{2}$ Department of General Medicine, Kasturba Medical College and Hospital, Mangalore, Manipal Academy of Higher Education, Manipal, Karnataka, India

${ }^{3}$ Department of Oral and Maxillofacial Pathology, Mahe Institute of Dental Sciences, Chalakkara, Puducherry, India

${ }^{5}$ Department of Oral and Maxillofacial Pathology, Manipal College of Dental Sciences, Mangalore, Manipal Academy of Higher Education, Manipal, Karnataka, India

Corresponding Author: Almas Binnal, Department of Oral Medicine and Radiology, Manipal College of Dental Sciences, Mangalore, Manipal Academy of Higher Education, Manipal, Karnataka, India, Phone: +91 824-2428716, e-mail: almas.binnal@manipal.edu

How to cite this article: Denny CE, Ramapuram J, Bastian TS, et al. Oral and Systemic Comorbidities and its Relation to Cluster of Differentiation 4 Counts in Human Immunodeficiency Virus Patients on Highly Active Antiretroviral Therapy: An Observational Study. World J Dent 2019;10(4):275-279.

Source of support: Nil

Conflict of interest: None

(O) The Author(s). 2019Open Access This article is distributed under the terms of the Creative Commons Attribution 4.0 International License (https://creativecommons. org/licenses/by-nc/4.0/), which permits unrestricted use, distribution, and non-commercial reproduction in any medium, provided you give appropriate credit to the original author(s) and the source, provide a link to the Creative Commons license, and indicate if changes were made. The Creative Commons Public Domain Dedication waiver (http://creativecommons.org/publicdomain/zero/1.0/) applies to the data made available in this article, unless otherwise stated. 
The oral cavity plays a key role in helping oral physicians in diagnosing the disease initially, as certain manifestations are characteristic of immune deterioration. Acquired immunodeficiency syndrome defining oral manifestations are hairy leukoplakia, nonHodgkins lymphoma, and Kaposi sarcoma. Candidiasis is found to be the most common opportunistic infection associated with HIV. ${ }^{7}$ Initiation of highly active antiretroviral therapy (HAART) has markedly reduced the pathognomic oral manifestations associated with HIV/AIDS. Systemic comorbidities are also seen in addition to oral manifestations in patients with HIV. The most common systemic comorbidities associated with this disease include pneumonia, tuberculosis, and systemic candidiasis.

Few studies have been reported in relation to CD4 count as well as oral and systemic comorbidities, especially in developing countries where there are limited medical facilities in the rural areas. Hence, this study was undertaken to assess the prevalence and types of oral and systemic comorbidity with laboratory parameter such as CD4 count.

\section{Materials and Methods}

A cross-sectional observational study was conducted among the HIV-positive patients on HAART therapy with oral manifestations. These patients were referred to the Department of Oral Medicine and Radiology, MCODS, Mangaluru, from Antiretroviral Therapy (ART) Centre in Kasturba Medical College and Hospital, Mangaluru, India, for evaluation of their oral lesions between January and June 2018.

Ethical approval for the study was obtained from the Institutional Ethics Committee. HIV infection was confirmed by enzyme-linked immune sorbent assay (ELISA) test and western blot. Information pertaining to demographic details (age, sex, marital status, occupation, and address), medical history, CD4 count, and currently prescribed HAART was collected. NACO guidelines were followed while examining each patient. ${ }^{8}$ Intraoral examination was carried out by an oral medicine specialist on a dental chair using a disposable dental mirror, probe, and sterile gauze pads under artificial light. The oral manifestations were noted and compared to the CDC classification of CD4 count as $\geq 500$ cells $/ \mu \mathrm{L}, 200-499$ cells $/ \mu \mathrm{L}$ and $<200$ cells $/ \mu \mathrm{L} .{ }^{9}$

The prevalence of systemic manifestation with respect to CD4 count was also noted. The data were entered into a Microsoft excel spread sheet and Statistical Package for the Social Sciences (SPSS 20.0). A Chi-square analysis was carried out to see the association of oral manifestations. $p<0.05$ was considered statistically significant.

\section{Results}

Of the 110 HIV positive patients included in the study, 50 patients had CD4 count $>500$ cells/ $\mu \mathrm{L}$ (mean $708.10 \pm 159.40$ ), 46 subjects had between 200 and 499 cells/ $\mu \mathrm{L}$ (mean $357.72 \pm 82.57$ ) and 14 had $<200$ cells $/ \mu \mathrm{L}$ (mean $120.64 \pm 62.28$ ). The mean CD4 count of the patients included in our study was $486.81 \pm 247.82$ cells $/ \mu \mathrm{L}$. Twenty-four patients had a history of using tobacco (smokeless/ smoke form). The habit-related manifestations were oral submucous fibrosis $(n=4,3.7 \%)$, leukoplakia $(n=9,8.3 \%)$, lichenoid reaction ( $n=4,3.7 \%)$, and oral cancer $(n=3,2.7 \%)$. Among the 3 patients with oral cancer, 2 had a CD4 count below $200(p<0.01)$. Leukoplakia and ranula in a patient with a CD4 count less than $200(p<0.025)$ was also observed. We also observed that lipoatrophy was more in men $(n=30,71.40 \%)$ than in women $(n=12,28.60 \%)$, which was statistically significant $(p<0.040)$. The oral manifestations among patients with CD4 $>500$ were dental caries $(60 \%)$, periodontitis (50\%), lipoatrophy (50\%), intraoral pigmentation (32\%), and candidiasis (22\%); CD4 count between 200 and 499 were dental caries (60.9\%), intraoral pigmentation (50\%), periodontitis (43.5\%), and lipoatrophy (30.5\%); and, in subjects with CD4 count $<200$ dental caries (64.3\%), periodontitis (50\%), and candidiasis $(42.9 \%)$ (Table 1).

Forty-three (39.09\%) of the subjects had systemic comorbidity, while the rest ( $n=55,50 \%$ ) had no comorbidities. The most common systemic comorbidity was pulmonary tuberculosis $(n=7, p<0.001)$ and extra pulmonary tuberculosis ( $n=25, p<0.001)$, pneumonia $(n=11, p<0.003)$ and pneumocystis pneumonia $(n=1, p<0.011)$, and systemic candidiasis $(n=3, p<0.001)$. While comparing the systemic disease to CD4 count, it was found that in patients with pulmonary tuberculosis, $28.60 \%$ had a CD4 count $<200$ and $6.50 \%$ had a CD4 count between 200 and 499 ( $p<0.001$ ) (Table 2). Among the extra pulmonary tuberculosis patients, $28.60 \%$ had a CD4 count $<200,32.60 \%$ had CD4 count between 200 and 499 and $12 \%$ had a CD4 count $>500$ ( $p<0.047)$. Two patients with a CD4 count $<200$ had hepatitis and liver cirrhosis, which was found to be statistically significant $(p<0.031$ ) (Table 3 ).

\section{Discussion}

An increase in CD4 count decreases the patient's susceptibility to various opportunistic infections and also reduces its advancement to AIDS and ultimately death. Thereby, CD4 count is a reliable marker of disease progression and treatment outcome in HIV and it is also an important factor to initiate both antiretroviral therapies in HIV patients. ${ }^{10}$ The correlation of oral manifestations with CD4 counts is well established. Hence, in the present study, we observed the oral manifestation and systemic comorbidity and compared it with CD4 count in patients undergoing HAART.

Dental caries and periodontitis were the most common oral manifestations among the three groups of the present study, which is similar to the study done by Davoodi et al. ${ }^{6}$ This could be either the effect of HAART ${ }^{11,12}$ or it could be due to the neglect of oral hygiene by the patient.

In our study, we found that lipoatrophy was more common in men, which is in accordance to a study done by Soares Flávia Machado Gonçalves and Costa Izelda Maria Carvalho. ${ }^{13}$ However, Price et al. noted that the prevalence of lipodystrophy in HIVinfected men was less, ${ }^{14}$ and while comparing it with CD4 count in our study, it was observed that lipoatrophy was more common in patients with CD4 count $>500$ and the least in patients with CD4 count $<200$. The reason for this could be that we had less patients with a CD4 count $<200$. There are reports of low prevalence of lipoatrophy in both developed and developing countries. This could be attributed to the difference in the combination of drugs used in the treatment, assessment of lipoatrophy, patient factors, etc. ${ }^{15}$ Lipoatrophy is usually associated with patients undergoing treatment with antiretroviral therapy. This facial wasting is called "face of AIDS."16 The loss of fat is most evident on the face when compared to the other parts. ${ }^{17}$

Intraoral pigmentation was observed more in patients with a CD4 count between 200 and 499; it could be either due to the use of melanocyte-stimulating drugs (antiretrovirals and antifungals) or due to an increased melanin production caused by the dysregulation of cytokines in HIV. ${ }^{18}$

Erythematous candidiasis was more common among the subjects with a CD4 count $<200(42.9 \%)$; this could be due to 
Table 1: Prevalence of oral manifestations in HIV patients in relation to CD4 count

\begin{tabular}{|c|c|c|c|c|c|}
\hline \multirow[b]{3}{*}{ Oral manifestations } & \multicolumn{3}{|c|}{ CD4 count } & \multirow[b]{3}{*}{ Chisquare } & \multirow[b]{3}{*}{$p$ value } \\
\hline & $<200$ & 200-499 & $>500$ & & \\
\hline & Number of patients (\%) & Number of patients (\%) & Number of patients (\%) & & \\
\hline Dental caries & $9(64.30)$ & $28(60.90)$ & $30(60.00)$ & 0.205 & 0.903 \\
\hline Periodontitis & $7(50.00)$ & $20(43.50)$ & $25(50.00)$ & 0.457 & 0.796 \\
\hline Intraoral pigmentation & $4(28.60)$ & $23(50.00)$ & $19(38.00)$ & 2.575 & 0.276 \\
\hline Lipoatrophy & $3(21.40)$ & $14(30.40)$ & $25(50.00)$ & 5.793 & 0.055 \\
\hline Candidiasis & $6(42.90)$ & $13(28.30)$ & $11(22.00)$ & 2.438 & 0.296 \\
\hline Gingivitis & $2(14.30)$ & $7(15.20)$ & $11(22.00)$ & 0.905 & 0.636 \\
\hline Aphthous ulcer & $2(14.30)$ & $2(4.30)$ & $2(4.00)$ & 2.432 & 0.296 \\
\hline Hairy leukoplakia & $1(7.10)$ & $2(4.30)$ & $1(2.00)$ & 0.94 & 0.625 \\
\hline Lichenoid reaction & $1(7.10)$ & $2(4.30)$ & $1(2.00)$ & 0.94 & 0.625 \\
\hline Postherepetic lesion & 0 & $1(2.20)$ & $2(4.00)$ & 0.751 & 0.687 \\
\hline Intraoral malignancy & $2(14.30)$ & $1(2.20)$ & 0 & 8.505 & 0.014 \\
\hline Xerostomia & 0 & $2(4.30)$ & $1(2.00)$ & 0.948 & 0.623 \\
\hline Linear gingival errythema & $1(7.10)$ & $1(2.20)$ & $1(2.00)$ & 1.182 & 0.554 \\
\hline Kaposi sarcoma & $1(7.10)$ & $1(2.20)$ & 0 & 3.182 & 0.204 \\
\hline
\end{tabular}

Table 2: Distribution associated with HIV infection of systemic disease

\begin{tabular}{llc}
\hline Comorbidity & Number of patients & Percentage \\
\hline Pneumonia $\left(p\right.$ value $\left.0.003^{*}\right)$ & 11 & 10.9 \\
Pneumocystis pneumonia $\left(p\right.$ value $\left.0.011^{*}\right)$ & 01 & 0.93 \\
Pulmonary TB $\left(p\right.$ value $\left.<0.001^{*}\right)$ & 07 & 6.48 \\
Extrapulmonary TB $\left(p\right.$ value $\left.<0.001^{*}\right)$ & 25 & 23.15 \\
Ischemic heart disease & 08 & 7.41 \\
Diabetes mellitus & 05 & 4.63 \\
Systemic candidiasis $\left(p\right.$ value $\left.<0.001^{*}\right)$ & 03 & 2.78 \\
Hypertension & 03 & 2.78 \\
Herpetic lesions & 02 & 1.85 \\
Anemia & 02 & 1.85 \\
Hepatitis & 01 & 0.93 \\
Epilepsy & 01 & 0.93 \\
Liver cirrhosis & 01 & 0.93 \\
Toxmoplasmosis CNS & 01 & 0.93 \\
Pleural effusion & 01 & 0.93 \\
\hline
\end{tabular}

${ }^{*} p$ value significant

the fact that the prevalence of fungal infections increased with the progression of the disease. The prevalence of erythematous candidiasis is comparable to the studies done by Nittayananta et al. ${ }^{19}$ and Gaurav et al. ${ }^{20}$

Other statistically significant oral lesions associated with HIV in patients with a CD4 count $<200$ were oral cancer and ranula. Oral cancer could occur as a result of the habit of smoking, chewing tobacco, and alcohol. It could also occur owing to increased cell growth and proliferation caused by viral interference with tumor suppressor proteins (p53, Rb) and activity of the HIV transactivator of transcription protein and HPV. ${ }^{21}$ Ranula is usually seen in the first or second decade of life, ${ }^{22,23}$ but in our study we had seen it in a 42-year-old man.

Kaposi's sarcoma was seen only in two patients; this could be due to a low prevalence of HHV 8 in Indian population. ${ }^{24}$ Among the two who had Kaposi's sarcoma, the CD4 count one patient had a CD4 $<200$, which is similar to the case reported by Moraes et al., ${ }^{25}$ and the second patient had a CD4 count between 200 and 499, which is similar to that reported by Vieira et al. ${ }^{26}$

Among the systemic comorbidities observed, the most prevalent were pulmonary tuberculosis, pneumonia, and systemic candidiasis. In HIV-infected patients, tuberculosis could be the initial sign of the HIV infection and is also the most common opportunistic infection. ${ }^{27}$ In India, of the estimated 5.1 million with HIV infection, half of them are co-infected with Mycobacterium tuberculosis. ${ }^{28}$

Pneumonia remains the main cause of morbidity and mortality in HIV patients. Pneumocystis pneumonia (PCP) is the most common AIDS-defining illness in the developed world, but the prevalence of PCP in India and also in patients on HAART ${ }^{29}$ is very low. This could be due to under diagnosis of $\operatorname{cases}^{30}$ another possibility of low prevalence could be due to the fact that all our patients were on HAART.

Candidiasis affecting the mucocutaneous system is the most prevalent opportunistic fungal infection in immunocompromised 
Table 3: Correlation between comorbidities and CD4 count

\begin{tabular}{|c|c|c|c|c|c|}
\hline \multirow[b]{2}{*}{ Comorbidity } & \multicolumn{3}{|c|}{ CD4 count } & \multirow[b]{2}{*}{ Chi square } & \multirow[b]{2}{*}{$p$ value } \\
\hline & $<200$ & 200-499 & $>500$ & & \\
\hline Pneumonia & 0 & $5(10.90)$ & $6(12)$ & 1.816 & 0.403 \\
\hline Pneumocystis pneumonia & 0 & 0 & $1(2)$ & 1.211 & 0.546 \\
\hline Pulmonary TB & $4(28.60)$ & $3(6.50)$ & 0 & 14.987 & 0.001 \\
\hline Extrapulmonary TB & $4(28.60)$ & $15(32.60)$ & $6(12)$ & 6.106 & 0.047 \\
\hline Toxmoplasmosis CNS & 0 & $1(2.20)$ & 0 & 1.404 & 0.496 \\
\hline Pleural effusion & 0 & $1(2.20)$ & 0 & 1.404 & 0.496 \\
\hline Diabetes mellitus & 0 & $4(8.70)$ & $1(2)$ & 3.239 & 0.198 \\
\hline Hypertension & 0 & $2(4.30)$ & $1(2)$ & 0.948 & 0.623 \\
\hline Herpes infection & 0 & 0 & $2(4)$ & 2.444 & 0.295 \\
\hline Systemic candidiasis & 0 & 0 & $3(6)$ & 3.701 & 0.157 \\
\hline Hepatitis & $1(7.10)$ & 0 & 0 & 6.92 & 0.031 \\
\hline Epilepsy & 0 & 0 & $1(2)$ & 1.211 & 0.546 \\
\hline Liver cirrhosis & $1(7.10)$ & 0 & 0 & 6.92 & 0.031 \\
\hline Anemia & $1(7.10)$ & 0 & $1(2)$ & 3.085 & 0.214 \\
\hline Ischemic heart disease & 0 & $4(8.70)$ & $4(8)$ & 1.275 & 0.529 \\
\hline
\end{tabular}

patients owing to the weakened immune system. ${ }^{31}$ Monitoring the infection helps us gain an insight into the disease progression and prevents a complication such as candidemia. ${ }^{32}$

The results of the present study must be viewed in relation to its limitations. Authors recommend further research in a larger sample and a comparison should also be done with patients not on HAART.

\section{ConcLusion}

From this study, we could analyze that oral lesions that were markers for HIV/AIDS are on the decline since the advent of HAART. The use of HAART has revolutionized HIV care and management. CD4 count is a relatively objective and simple marker of HIV. Increase in CD4 count reduces the frequency of opportunistic infections, progression to AIDS, and death. Hence, timely diagnosis and early treatment of both oral and systemic comorbidities could help the patients to have a better quality of life.

\section{References}

1. UNAIDS. 2018 Global AIDS Update: Miles to go-closing gaps, breaking barriers, righting injustices; July 2018.

2. National AIDS Control Organization \& ICMR-National Institute of Medical Statistics (2018). HIV Estimations 2017: Technical Report. New Delhi: NACO, Ministry of Health and Family Welfare, Government of India.

3. Dalgleish AG, Beverly PCL, et al. The CD4 (T4) antigen is an essential component of the receptor for the AIDS retrovirus. Nature 1984;312:763-767. DOI: 10.1038/312763a0.

4. Brenchley JM, Schacker TW, et al. CD4+ T cell depletion during all stages of HIV disease occurs predominantly in the gastrointestinal tract. J Exp Med 2004;200:749-759. DOI: 10.1084/jem. 20040874.

5. Berberi A, Aoun G. Oral lesions associated with human immunodeficiency virus in 75 adult patients: a clinical study. J Korean Assoc Oral Maxillofac Surg 2017;43:388-394. DOI: 10.5125/ jkaoms.2017.43.6.388.

6. Davoodi P, Hamian M, et al. Oral Manifestations Related to CD4 Lymphocyte Count in HIV-Positive Patients. J Dent Res Dent Clin Dent Prospect 2010;4(4):115-119. DOI: 10.5681/joddd. 2010.029.
7. Menezes TO, Rodrigues MC, et al. Oral and systemic manifestations in HIV-1 patients. Rev Soc Bras Med Trop 2015;48(1):83-86. DOI: 10.1590/0037-8682-0179-2014.

8. National Guidelines on Prevention, Management and Control of Reproductive Tract Infections including Sexually Transmitted Infections, August 2007.

9. Centers for Disease Control and Prevention. 1993 revised classification system for HIV infection and expanded surveillance case definition for AIDS among adolescents and adults. MMWR Recomm Rep 1992 Dec 18; 41(RR-17):1-19. Accessed December 1, 2013.

10. Hoffman J, Griensven JV, et al. Role of the CD4 count in HIV management. HIV Ther 2010;4:27-39. DOI: 10.2217/hiv.09.58.

11. Hodgson TA, Greenspan D, et al. Oral lesions of HIV diseases and HAART in industrialized countries. Adv Dent Res 2006;19:57-62. DOI: 10.1177/154407370601900112.

12. de Faria PR, Vargas PA, et al. Tongue disease in advanced AIDS. Oral Dis 2005;11:72-80. DOI: 10.1111/j.1601-0825.2004.01070.x.

13. Gonçalves SFM, Carvalho CIM. Treatment of HIV-associated facial lipoatrophy: impact on infection progression assessed by viral load and CD4 count. An Bras Dermatol 2013 Aug;88(4):570-577. DOI: 10.1590/abd1806-4841.2013895.

14. Price J, Hoy J, et al. Changes in the prevalence of lipodystrophy, metabolic syndrome and cardiovascular disease risk in HIV-infected men. Sex Health 2015 Jun;12(3):240-248. DOI: 10.1071/SH14084.

15. Iwuala SO, Lesi OA, et al. Prevalence of and Risk Factors for Lipoatrophy in Patients with HIV Infection in Nigeria. AIDS Res Treat 2015;2015:402638. DOI: 10.1155/2015/402638.

16. Soares FMG, Costa IMC. Facial lipoatrophy and AIDS. Barros E. HIV Infection - Impact, Awareness and Social Implications of living with HIV/AIDS. InTech; 2011. pp. 61-80.

17. Baril JG, Junod P, et al. HIV-associated lipodystrophy syndrome: A review of clinical aspects. Can J Infect Dis Med Microbiol 2005;16: 233-243.

18. Aškinyte $D$, Matulionyte $R$, et al. Oral manifestations of HIV disease: A review. Stomatologija 2015;17(1):21-28.

19. Nittayananta W, Chanowanna N, et al. Risk factors associated with oral lesions in HIV infected heterosexual people and intravenous drug users in Thailand. J Oral Pathol Med 2001;30(4):224-230. DOI: 10.1034/j.1600-0714.2001.300406.x.

20. Gaurav S, Keerthilatha PM, et al. Prevalence of Oral Manifestations and Their Association with CD4/CD8 Ratio and HIV Viral Load in South India. Int J Dent 2011;2011:964278. DOI: 10.1155/2011/ 964278. 
21. Epstein JB. Oral malignancies associated with HIV.J Can Dent Assoc 2007;73(10):953-956.

22. Chidzonga MM, Rusakaniko S. Ranula: another HIV/AIDS associated oral lesion in Zimbabwe. Oral Diseases 2004;10:229-232. DOI: 10.1111/j.1601-0825.2004.01013.x.

23. Syebele K, Munzhelele T. Oral mucocele/ranula: Another human immunodeficiency virus-related salivary gland disease. Laryngoscope 2015;125:1130-1136. DOI: 10.1002/lary.25058.

24. Kura MM, Khemani UN, et al. Kaposi's sarcoma in apatient with AIDS. J Assoc Physicians India 2008;56:262-264.

25. de Moraes M, Vasconcelos M, et al. Solitary Kaposi's sarcoma in retromolar region of an HIV positive patient: case report. J Bras Patol Med Lab 2012;48(1):45-49. DOI: 10.1590/S1676-24442012000100009.

26. Vieira F, Somerville J, et al. Oral Kaposi's Sarcoma in HIV Positive Patients. A Case Report and a Review of Literature. J AIDS Clin Res 2014;5:349.
27. Padmapriyadarsini C, Narendran G, et al. Diagnosis \& treatment of tuberculosis in HIV co-infected patients. Indian J Med Res 2011;134:850-865. DOI: 10.4103/0971-5916.92630.

28. Sharma SK, Mohan A, et al. HIV-TB co-infection: epidemiology, diagnosis \& management. Indian J Med Res 2005;121:550-567.

29. Feldman C. Pneumonia associated with HIV infection. Curr Opin Infect Dis 2005;18:165-170.

30. Kumarasamy N, Vallabhaneni $\mathrm{S}$, et al. Clinical profile of HIV in India. Indian J Med Res 2005;121:377-394.

31. Monika M, Kaur R, et al. Candida Species Prevalence Profile in HIV Seropositive Patients from a Major Tertiary Care Hospital in New Delhi, India. J Pathog 2016;2016:6204804. DOI: 10.1155/2016/ 6204804.

32. Anwar KP, Malik A, et al. Profile of candidiasis in HIV infected patients. Iran J Microbiol 2012;4:204-209. 